\title{
The Diagnostic Value of Alpha-1-Antitrypsin Phenotype in Patients with Granulomatosis with Polyangiitis
}

\author{
M. Y. Pervakova, ${ }^{1}$ V. L. Emanuel, ${ }^{1}$ O. N. Titova, ${ }^{1}$ S. V. Lapin, ${ }^{1}$ V. I. Mazurov, ${ }^{2}$ \\ I. B. Belyaeva, ${ }^{2}$ A. L. Chudinov, ${ }^{2}$ T. V. Blinova, ${ }^{1}$ and E. A. Surkova ${ }^{1}$ \\ ${ }^{1}$ First Pavlov State Medical University of St. Petersburg, Saint Petersburg 197022, Russia \\ ${ }^{2}$ North-Western Mechnikov State Medical University, Saint Petersburg 191015, Russia \\ Correspondence should be addressed to M. Y. Pervakova; margaritalerner@gmail.com
}

Received 28 January 2016; Revised 9 March 2016; Accepted 27 March 2016

Academic Editor: Ruben Burgos-Vargas

Copyright (C) 2016 M. Y. Pervakova et al. This is an open access article distributed under the Creative Commons Attribution License, which permits unrestricted use, distribution, and reproduction in any medium, provided the original work is properly cited.

The deficiency of alpha-1 protease inhibitor, or alpha-1-antitrypsin (A1AT), predisposes to chronic lung diseases and extrapulmonary pathology. Besides classical manifestations, such as pulmonary emphysema and liver disease, alpha-1-antitrypsin deficiency (A1ATD) is also known to be associated with granulomatosis with polyangiitis (GPA or Wegener's granulomatosis). The aim of our study was to evaluate the frequency of allelic isoforms of A1AT and their clinical significance among GPA patients. Detailed clinical information, including Birmingham Vasculitis Activity Score (BVAS), incidence of lung involvement, anti-proteinase 3 (PR3) antibodies concentrations, and other laboratory data were collected in 38 GPA patients. We also studied serum samples obtained from 46 healthy donors. In all collected samples A1AT phenotyping by isoelectrofocusing (IEF) and turbidimetric A1AT measurement were performed. Abnormal A1AT variants were found in 18.4\% (7/38) of cases: $1 \mathrm{ZZ}, 4 \mathrm{MZ}, 2 \mathrm{MF}$, and only $1 \mathrm{MZ}$ in control group (2\%). The mean A1AT concentration in samples with atypical A1AT phenotypes was significantly lower $(P=0.0038)$ than in normal A1AT phenotype. We found that patients with abnormal A1AT phenotypes had significantly higher vasculitis activity (BVAS) as well as anti-PR3 antibodies concentration. We conclude that A1AT deficiency should be considered in all patients with GPA.

\section{Introduction}

Granulomatosis with polyangiitis (Wegener's, GPA) is a disease manifested by necrotizing granulomatous inflammation affecting predominantly small to medium vessels and associated with presence of antineutrophil cytoplasmic antibodies (ANCA) in blood. Upper respiratory tract, eyes, lungs, and kidneys are typical target organs; rarely skin, joints, and nervous system are also involved [1]. This type of vasculitis is rare (annual frequency in Northern Europe is lower than 1:100000), but quite aggressive disease, which results in lethal outcome in $90 \%$ of cases during first year if left untreated [2]. An elevated frequency of alpha-1-antitrypsin (A1AT) phenotypic variants was found in GPA patients in comparison with population incidence [3].

A1AT is an acute phase protein belonging to the serine proteases inhibitors family and is capable of inactivating many proteases including proteinase 3 that is recognized as the main autoantigenic target in GPA (PR3) [4]. Alpha-1antitrypsin deficiency (A1ATD) is a frequent genetic disorder caused by low serum A1AT concentration as a result of carriage of pathogenic alleles of Pi-gene (protease inhibitor) [5]. The deficiency of this important protective factor leads to different types of lung tissue injury, such as emphysema or destructive inflammation in GPA [6].

The most common and normally functioning A1AT allelic form is PiM, so healthy human phenotype is designated as PiMM. There are more than 100 genetic AlAT variants, among which PiZ and PiS are the most common and clinically significant. A1ATD becomes clinically manifested in individuals carrying mutation in both gene $\mathrm{Pi}$ alleles, especially in PiZZ variant, whereas in heterozygous state the defect is partly compensated by normal allele that is found in individuals with PiMZ and PiMS phenotypes [7]. Heterozygous A1AT carriage does not provide high risk of AlATD, though it predisposes to some diseases, including GPA [8]. 
According to the statistical data of American Thoracic Society/European Respiratory Society (ATS/ERS), the frequency of Z-alleles in GPA patients in Europe varies from 9 to $17.6 \%$ [9]. Quantitative methods, like turbidimetric measurement, are generally used for the laboratory detection of A1AT [10]. However, the diagnostic efficacy of these assays is limited, because the result might be incorrect due to crossreactivity with lipids or haemoglobin [9], or acute phase reaction [11]. Reference method of screening for A1ATD is isoelectrofocusing (IEF) $[12,13]$ with selective A1AT staining with polyclonal anti-A1AT antibodies [14, 15].

The aim of our study was to evaluate the frequency of pathogenic A1AT alleles among Russian GPA patients and to find out whether A1AT phenotype influences vasculitis activity.

\section{Materials and Methods}

Serum samples and clinical data were provided by SaintPetersburg Clinical Rheumatology Hospital number 25. 38 sera were obtained from individuals, suffering from active anti-PR3-positive GPA. 46 samples of healthy blood donors were collected as a control group. To estimate the clinical significance of different A1AT phenotypic variants, we collected detailed clinical and laboratory data, including Birmingham Vasculitis Activity Score (BVAS), the incidence of lung involvement, and anti-PR3 antibodies concentrations, measured by enzyme-linked immunosorbent assay (ELISA) with a commercial kit (Euroimmun, Germany).

We determined A1AT phenotypes in all collected samples by IEF with immunoblotting with the use of horizontal electrophoresis system (Pharmacia, Sweden). PH gradient was created by adding narrow specter ampholytes $\mathrm{pH} 4.2-$ 4.9 (GE Healthcare, Sweden). The A1AT molecules focused within agarose gel were blotted onto nitrocellulose paper and selectively stained by horseradish peroxidase conjugated goat anti-A1AT antibodies (Bethyl Laboratories, Sweden). A1AT phenotypes were assessed by comparing A1AT migration patterns with control PiMM, PiMZ, and PiMS samples.

Electrophoretic patterns of main A1AT isoforms migration by IEF are demonstrated in Figure 1.

Besides phenotyping, quantitative A1AT measurements were performed with turbidimetric commercial kit (Sentinel Diagnostics, Italy).

To estimate statistical significance we compared clinical and laboratory parameters of the groups, using unpaired $t$ test or Mann-Whitney $U$ test, depending on whether the distribution was Gaussian. All categorical variables were compared with exact Fisher test. Differences between the groups were considered to be significant at a $P$ value of $<0.05$. Statistical analysis was performed using Graph Pad Prism 4.0 software.

\section{Results}

We observed 38 GPA patients receiving inpatient treatment at specialized rheumatologic clinic. The group was heterogeneous by gender (16 men and 22 women) and by age (18-77 years old). All samples were anti-PR-3 ANCA-positive.

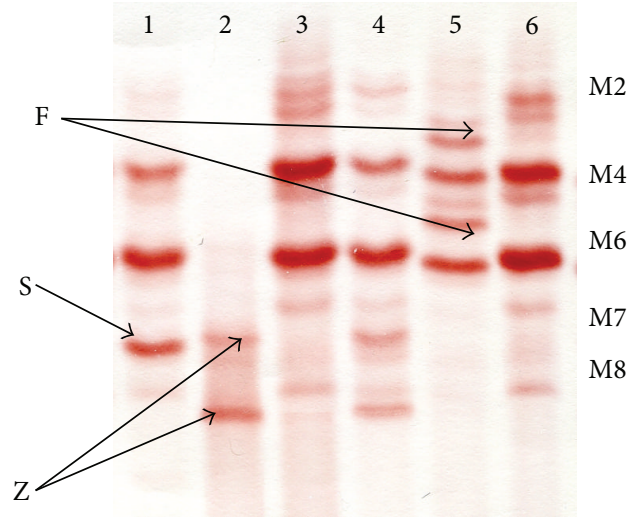

FIGURE 1: Examples of A1AT phenotype patterns, obtained by IEF. Track 1: PiMS. Track 2: PiZZ. Track 3: PiMM. Track 4: PiMZ. Track 5: PiMF. Track 6: PiMM. A1AT: alpha-1-antitrypsin. IEF: isoelectrofocusing. M2, M4, M6, M7, and M8: zones of migration of main A1AT isoforms in normal PiMM phenotype, detected by IEF. $\mathrm{F}, \mathrm{Z}$, and $\mathrm{S}$ : additional bands with another migration, indicating the presence of PiF, PiS, and PiZ alleles.

Pulmonary involvement in vasculitis was found in $64.5 \%$ $(20 / 31)$ of cases and was presented by cavitating infiltrates $(N=13)$ and interstitial fibrosis $(N=7)$. All patients had a different degree of vasculitis activity, which was evaluated with BVAS clinical scale. In GPA patients, we found $18.4 \%$ (7/38) pathologic A1AT variants. Following A1AT phenotypes were identified: $4 \mathrm{MZ}, 1 \mathrm{ZZ}$, and $2 \mathrm{MF}$. Among 46 samples of healthy donor's sera 1 heterozygous PiMZ phenotype was found.

Some clinical and laboratory parameters of 7 GPA patients, carrying pathological A1AT phenotypes, are demonstrated in Table 1.

To find out clinical significance of pathogenic A1AT allelic forms, we analyzed GPA patients depending on A1AT phenotype. Mean A1AT concentrations in groups with normal $(N=31)$ and pathological $(N=7)$ A1AT phenotypes were $1840 \mathrm{mg} / \mathrm{L} \pm 127.2$ and $970.0 \mathrm{mg} / \mathrm{L} \pm 167.6$, respectively $(P=$ 0.0038 , unpaired $t$-test). A1AT concentrations in both groups are presented in Figure 2.

Only in 2 from 7 samples with abnormal A1AT phenotype the A1AT concentrations were below the reference range of $900 \mathrm{mg} / \mathrm{L}$.

Comparing A1AT phenotypes and clinical data, we found that the mean vasculitis activity, measured with BVAS, in the group with normal phenotypes was $16.42 \pm 1.498$ that was significantly lower than $24.00 \pm 2.828$, the mean BVAS score in GPA patients with abnormal A1AT (see Figure 3).

Concentrations of anti-PR3 antibodies were also significantly higher $(P=0.0480$, Mann-Whitney $U$ test $)$ in GPA patients with abnormal A1AT phenotypes $(180.4 \mathrm{RU} / \mathrm{mL} \pm$ 35.19 and 106.0 $\mathrm{RU} / \mathrm{mL} \pm 18.25$, resp.).

Mean values of erythrocyte sedimentation rate (ESR) in patients with abnormal A1AT phenotypes were also statistically higher than in patients with normal phenotypes: $35.70 \mathrm{~mm} / \mathrm{h} \pm 3.278$ and $55.67 \mathrm{~mm} / \mathrm{h} \pm 2.031$, respectively, $P=$ 0.0054 . The differences in other inflammation markers, such 
TABLE 1: The description of clinical data of GPA patients with pathological AlAT phenotypes.

\begin{tabular}{|c|c|c|c|c|c|c|c|}
\hline Number & 1 & 2 & 3 & 4 & 5 & 6 & 7 \\
\hline Gender & Male & Male & Male & Female & Female & Female & Female \\
\hline Age & 31 & 19 & 49 & 62 & 52 & 58 & 67 \\
\hline Disease duration (years) & 8 & 1 & 3 & 1 & 1 & 1 & 8 \\
\hline Lung involvement type & $\begin{array}{l}\text { Cavitating } \\
\text { infiltrates }\end{array}$ & $\begin{array}{l}\text { Cavitating } \\
\text { infiltrates }\end{array}$ & $\begin{array}{l}\text { Interstitial } \\
\text { fibrosis }\end{array}$ & $\begin{array}{l}\text { Cavitating } \\
\text { infiltrates }\end{array}$ & $\begin{array}{l}\text { Cavitating } \\
\text { infiltrates }\end{array}$ & $\begin{array}{l}\text { Cavitating } \\
\text { infiltrates }\end{array}$ & $\begin{array}{l}\text { Interstitial } \\
\text { fibrosis }\end{array}$ \\
\hline BVAS activity & 28 & 26 & 14 & 20 & 28 & 38 & 14 \\
\hline A1AT phenotype & $\mathrm{MZ}$ & $\mathrm{ZZ}$ & $\mathrm{MZ}$ & MF & $\mathrm{MZ}$ & MF & $\mathrm{MZ}$ \\
\hline $\begin{array}{l}\text { A1AT concentration } \\
(\mathrm{mg} / \mathrm{L})^{*}\end{array}$ & 1041 & 345 & 1033 & 1057 & 430 & 1576 & 1308 \\
\hline $\begin{array}{l}\text { Anti-PR3-antibodies } \\
\text { concentration }(\mathrm{RU} / \mathrm{mL})^{* *}\end{array}$ & 25.0 & 260.5 & 135.1 & 116.0 & 266.0 & 330.9 & 129.4 \\
\hline ESR $(\mathrm{mm} / \mathrm{hr})$ & 54 & 57 & 46 & 54 & 63 & 60 & 55 \\
\hline
\end{tabular}

Note:

*A1AT reference values: 900-2000 mg/L.

**Anti-PR3 antibodies reference values: <20 RU/mL.

GPA, granulomatosis with polyangiitis; BVAS, Birmingham Vasculitis Activity Score; A1AT, alpha-1-antitrypsin; PR3, proteinase 3; ESR, erythrocyte sedimentation rate.

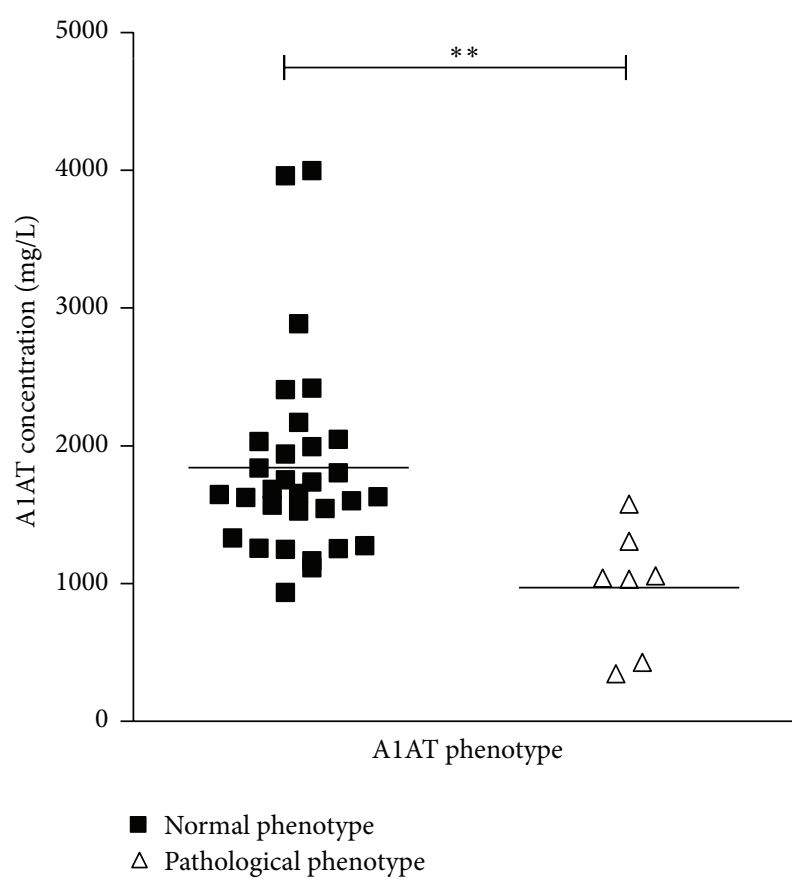

Figure 2: The results of quantitative A1AT measurement in serum samples of GPA patients with normal and pathological A1AT phenotypes; ${ }^{* *} P<0.01$. Note: A1AT reference values: $900-$ $2000 \mathrm{mg} / \mathrm{L}$.

as fibrinogen, C-reactive protein, IgG, circulating immune complexes, and complement $\mathrm{C} 3$ did not reach statistical significance.

We noted that pulmonary involvement was found in all GPA patients with abnormal AlAT phenotype $(N=7)$ and only in $65 \%(20 / 31)$ patients with normal A1AT, although this difference was not statistically significant.

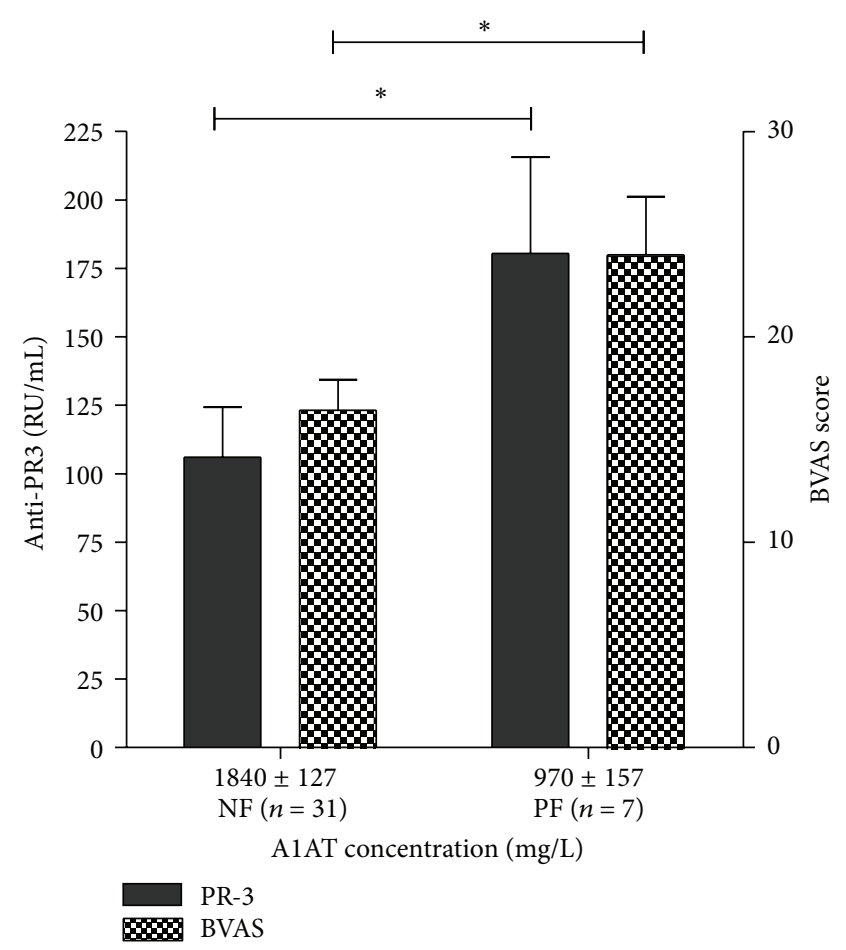

FIGURE 3: A1AT concentration, anti-PR3 antibodies concentration, and GPA activity in patients with normal and abnormal A1AT phenotypes; ${ }^{*} P<0.1$. NF-patients with normal A1AT phenotype; PF-patients with pathological A1AT phenotype; A1AT: alpha-1antitrypsin; PR3: Proteinase 3, anti-PR3: anti-proteinase 3 antibodies; GPA: Granulomatosis with polyangiitis; BVAS: Birmingham Vasculitis Activity Score.

\section{Discussion}

To analyze the incidence of abnormal phenotypic variants of A1AT among Russian GPA patients, we studied 38 serum 
samples from individuals suffering from this disease. We determined A1AT phenotype and measured its concentration in all serum samples. We found abnormal A1AT phenotypes in $18.4 \%$ of cases, over the number shown in other publications: 9-17.6\% [9].

We found higher BVAS activity, greater concentrations of anti-PR3 antibodies, and higher ESR in GPA patients carrying atypical alleles of A1AT. These data suggest that GPA is more severe in these individuals and more effective treatment in such cases may be considered.

Our findings can be explained by the fact that A1AT modulates PR3 activity and therefore it is presumably an important protective factor in systemic vasculitis. Tissue inflammation induces PR3 expression by neutrophils; this is attended by oxidative burst and partial neutrophil degranulation. PR3 also stimulates IL-8 production by endotheliocytes and monocytes and promotes increase of eicosanoids level and release of leucotriene B4, launching aggressive necrotizing inflammatory cascade in GPA [16-18]. It was experimentally proved that ANCA inhibit inactivation of PR3 by A1AT molecule, when bound to PR3 in GPA patient's serum [19]. Thus PR3 exhibits proinflammatory activity; meanwhile A1AT antagonizes PR3, influencing both PR3 itself and PR3 induced neutrophil chemotaxis.

The interaction of A1AT and PR3 may have a considerable influence on severity of inflammatory process in GPA and can be impaired in case of abnormal A1AT phenotype.

The case of successful A1AT replacement treatment of individual suffering from GPA and A1ATD has been reported. When this patient with AlATD and GPA, resistant to standard therapy, was given replacement therapy with A1AT, she developed stable remission of GPA with regression of skin lesions and improvement of pulmonary parameters [20].

\section{Conclusions}

The laboratory testing for pathological A1AT alleles is not usually ordered for patients with systemic vasculitides in routine clinical practice. Considering relatively high frequency of pathological A1AT phenotype carriage among GPA patients and its clinical significance we may conclude that the relevance of A1ATD is underestimated. During medical examination of every GPA patient, the possibility of A1AT deficiency should be considered.

\section{Competing Interests}

The authors declare that they have no competing interests.

\section{Acknowledgments}

This research was supported by the Russian Scientific Foundation (agreement no. 16-15-00118).

\section{References}

[1] J. C. Jennette, R. J. Falk, P. A. Bacon et al., "2012 Revised International Chapel Hill Consensus Conference nomenclature of vasculitides," Arthritis \& Rheumatism, vol. 65, no. 1, pp. 1-11, 2013.

[2] M. Bohm, M. I. Gonzalez Fernandez, S. Ozen et al., "Clinical features of childhood granulomatosis with polyangiitis (wegener's granulomatosis)," Pediatric Rheumatology, vol. 12, article 18, 2014.

[3] A. D. Mahr, J. C. Edberg, J. H. Stone et al., "Alpha 1-antitrypsin deficiency-related alleles $\mathrm{Z}$ and $\mathrm{S}$ and the risk of Wegener's granulomatosis," Arthritis Care and Research, vol. 62, no. 12, pp. 3760-3767, 2010.

[4] D. E. Jenne, J. Tschopp, J. Lüdemann et al., "Wegener's autoantigen decoded," Nature, vol. 346, no. 6284, p. 520, 1990.

[5] V. Boulyjenkov, " $\alpha 1$-antitrypsin deficiency: memorandum from a WHO meeting," Bulletin of the World Health Organization, vol. 75, no. 5, pp. 397-415, 1997.

[6] S. Gadre, J. Stoller, and A. Mehta, "Granulomatosis with polyangiitis and associated pulmonary emphysema: breathtaking vasculitis," Lung India, vol. 32, no. 4, pp. 367-369, 2015.

[7] D. F. Keren, Ed., Protein Electrophoresis in Clinical Diagnosis, Edward Arnold, London, UK, 2003.

[8] L. Fregonese and J. Stolk, "Hereditary alpha-1-antitrypsin deficiency and its clinical consequences," Orphanet Journal of Rare Diseases, vol. 3, article 16, 2008.

[9] "American Thoracic Society/European Respiratory Society statement: standards for the diagnosis and management of individuals with alpha-1 antitrypsin deficiency," American Journal of Respiratory and Critical Care Medicine, vol. 168, no. 7, pp. 818900, 2003.

[10] T. J. Craig, "Suspecting and Testing for $\alpha$-1 antitrypsin deficiency-an allergist's and/or immunologist's perspective," The Journal of Allergy and Clinical Immunology. In Practice, vol. 3, no. 4, pp. 506-511, 2015.

[11] B. PopŁawska, S. Janciauskiene, and J. ChorostowskaWynimko, "Genetic variants of alpha-1 antitrypsin: classification and clinical implications," Pneumonologia $i$ Alergologia Polska, vol. 81, no. 1, pp. 45-54, 2013.

[12] M. Y. Pervakova, V. L. Emanuel, E. A. Surkova et al., "Comparison of electrophoresis, immunoturbidimetric measurement and phenotyping of alpha-1-antitrypsin for the diagnosis of alpha-1antitrypsin deficiency," Kliniceskaja Laboratornaja Diagnostika, vol. 10, pp. 28-31, 2015.

[13] M. Y. Pervakova, S. V. Lapin, A. L. Chudinov et al., "Laboratory detection of $\alpha$-1-antitrypsin deficiency in patients suffering from chronical lung pathology," Modern Laboratory, vol. 18, no. 259, pp. 32-37, 2015.

[14] J.-O. Jeppsson, B. Franzen, and D. Wilson Cox, "Typing of genetic variants of $\alpha 1$-antitrypsin by electrofocusing," Clinical Chemistry, vol. 28, no. 1, pp. 219-225, 1982.

[15] D. N. Greene, M. C. Elliott-Jelf, J. A. Straseski, and D. G. Grenache, "Facilitating the laboratory diagnosis of $\alpha 1$ antitrypsin deficiency," American Journal of Clinical Pathology, vol. 139, no. 2, pp. 184-191, 2013.

[16] S. P. Berger, M. A. J. Seelen, P. S. Hiemstra et al., "Proteinase 3, the major autoantigen of Wegener's granulomatosis, enhances IL-8 production by endothelial cells in vitro," Journal of the American Society of Nephrology, vol. 7, no. 5, pp. 694-701, 1996.

[17] F. Grimminger, K. Hattar, C. Papavassilis et al., "Neutrophil activation by anti-proteinase 3 antibodies in Wegener's granulomatosis: role of exogenous arachidonic acid and leukotriene B4 generation," Journal of Experimental Medicine, vol. 184, no. 4, pp. 1567-1572, 1996. 
[18] D. R. Ralston, C. B. Marsh, M. P. Lowe, and M. D. Wewers, "Antineutrophil cytoplasmic antibodies induce monocyte IL8 release: role of surface proteinase- $3, \alpha 1$-antitrypsin, and Fc $\gamma$ receptors," Journal of Clinical Investigation, vol. 100, no. 6, pp. 1416-1424, 1997.

[19] B. A. van de Wiel, K. M. Dolman, C. H. van der Meer-Gerritsen, C. E. Hack, A. E. G. K. Von Dem Borne, and R. Goldschmeding, "Interference of Wegener's granulomatosis autoantibodies with neutrophil Proteinase 3 activity," Clinical and Experimental Immunology, vol. 90, no. 3, pp. 409-414, 1992.

[20] J. M. Hernandez Perez, S. Fumero Garcia, and A. Alvarez Pio, "Successful alphal-antitrypsin replacement therapy in a patient with alphal-antitrypsin deficiency and granulomatosis with polyangiitis," Rheumatology (Oxford), vol. 52, no. 4, pp. 755-757, 2013. 


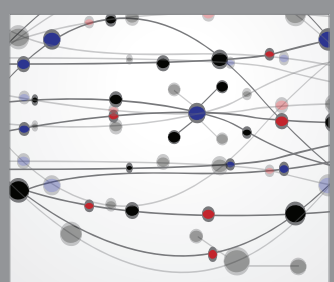

The Scientific World Journal
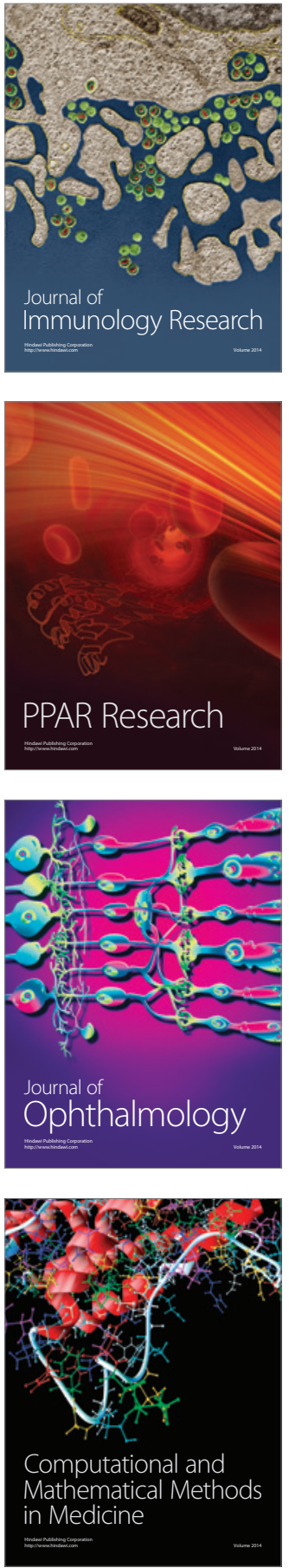

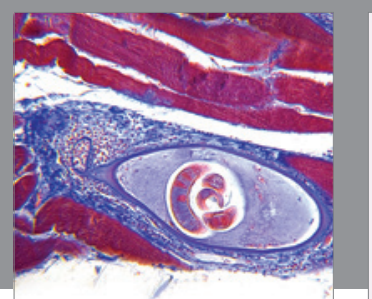

Gastroenterology Research and Practice

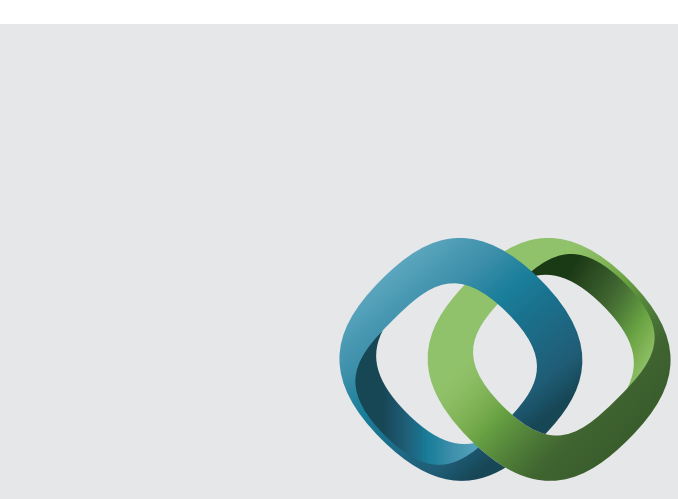

\section{Hindawi}

Submit your manuscripts at

http://www.hindawi.com
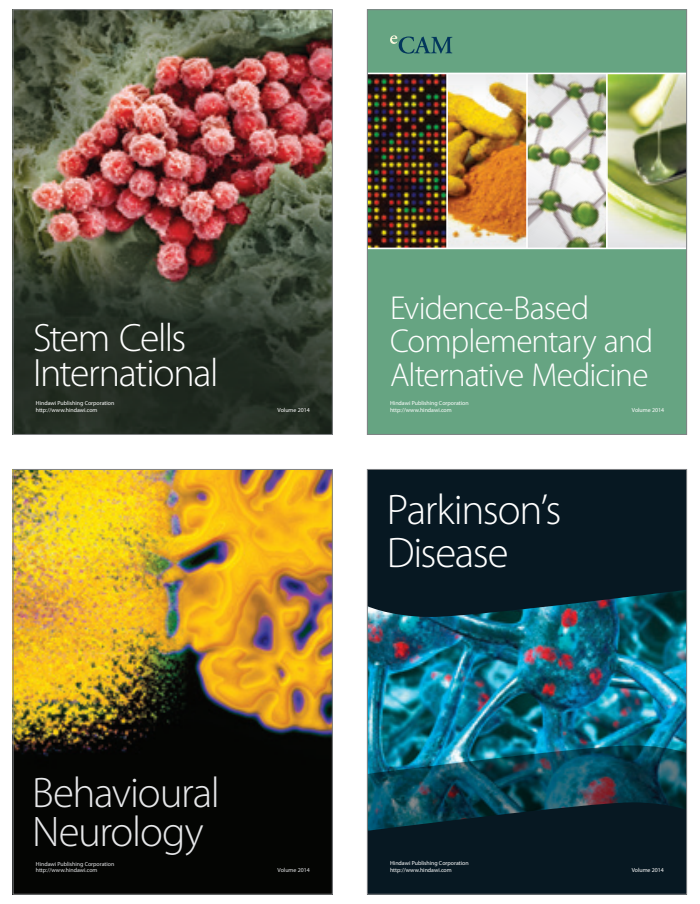
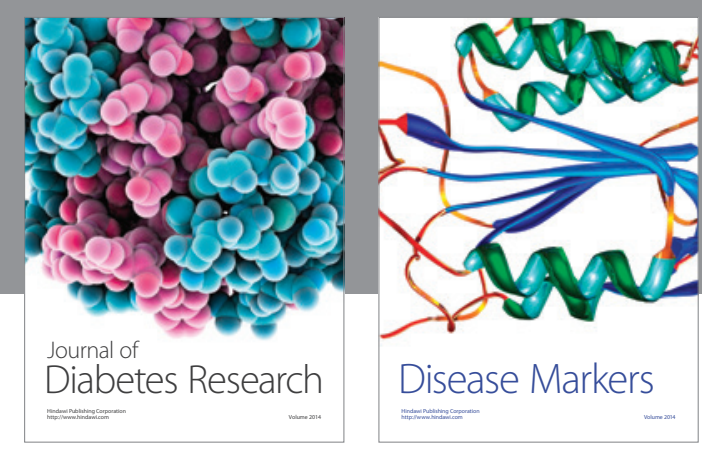

Disease Markers
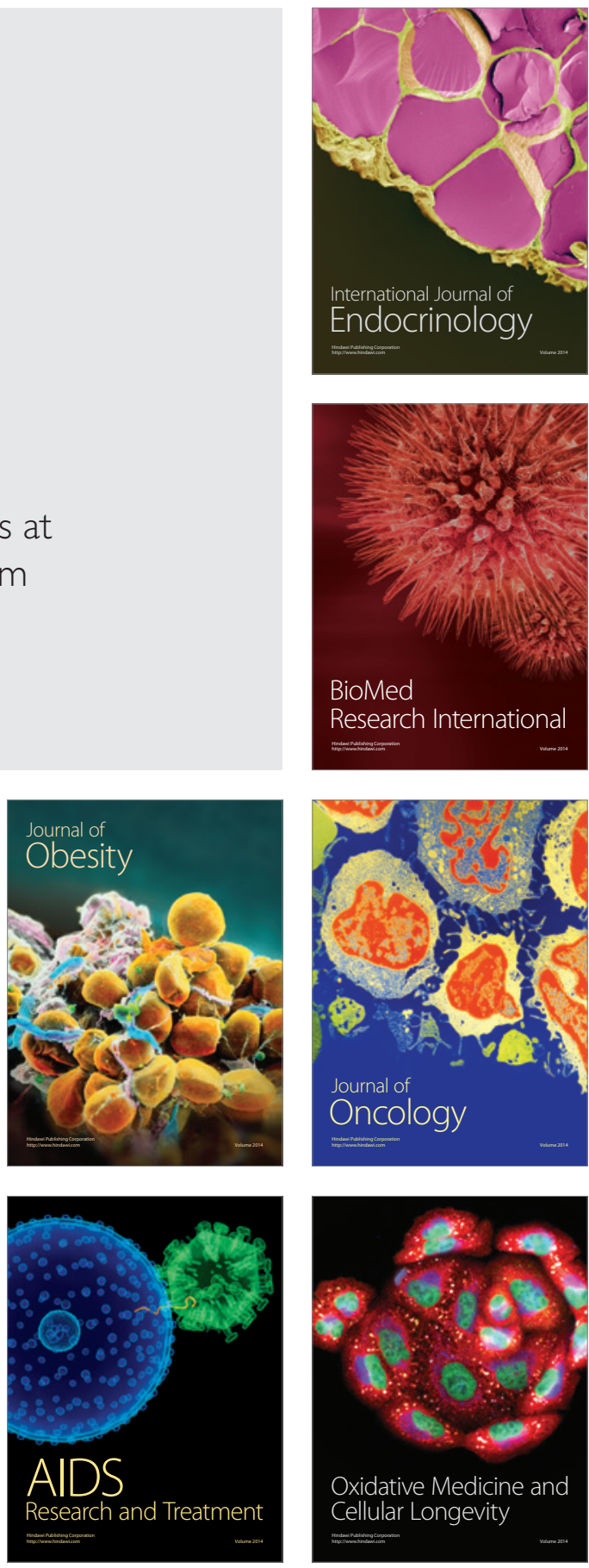